Casos Clínicos

Arch. Esp. Urol., 59, 8 (816-820), 2006

\section{CARCINOMA UROTELIAL DE ALTO GRADO VESICAL CON PATRÓN DE CÉLULAS "EN ANILLO DE SELLO". A PROPÓSITO dE UN CASO.}

\author{
F. J. Torres Gómez, A. García Escudero' y F. J. Torres \\ Olivera?.
}

Servicio de Anatomía Patológica. Hospital de Jerez de la Frontera. Cádiz. y Dpto de Anatomía Patológica'. Hospital Universitario Virgen Macarena. Sevilla. España.

Resumen.- OBJETIVO: La presencia de células "en anillo de sello" constituye un factor de mal pronóstico en aquellas neoplasias uroteliales, generalmente de alto grado, que las presentan.

MÉTODO: Presentamos el caso de un varón de 69 años diagnosticado de carcinoma urotelial de alto grado con patrón de células "en anillo de sello" cuyo diagnóstico pudo ser intuido en los estudios citológicos seriados que se realizaron tras el debut clínico.

RESULTADOS: Para la realización de tal diagnóstico es preciso descartar la posibilidad de que estemos ante la metástasis o infiltración de una neoplasia de otra localización.

CONCLUSIONES: La presencia de neoplasia "in situ" o bien la coexistencia de un componente urotelial infiltrante ayudan a determinar el origen primario de tales neoplasias.

Francisco Javier Torres Gómez

Plaza de la Encarnación 32 P1 2B

41003. Sevilla. (España)

javiertorresgomez@yahoo.es

Trabajo recibido: 30 de enero 2006
Palabras clave: Anillo de sello. Urotelial. Inclusiones citoplasmáticas.

Summary.- OBJECTIVE: The presence of signet ring cells within a transitional cell carcinoma is a factor of poor prognosis.

METHODS: We report the case of a 69-year-old male patient with the diagnosis of high grade transitional cell carcinoma with signet ring cell pattern, the presence of which could have been foreseen in serial cytological tests performed after the clinical debut.

RESULTS: To achieve such a diagnosis, it is necessary to rule out the possibility of metastasis or infiltration of a neoplasia from other organ.

CONCLUSION: Both the presence of an in situ neoplasia or the coexistence of infiltrative transitional cell tumor can help to determine primary origin of these neoplasias.

Keywords: Signet ring cell. Urothelial.

\section{INTRODUCCIÓN}

El carcinoma urotelial es la neoplasia más frecuente en el tracto urinario y la vejiga urinaria no es una excepción si bien existe una gran variedad de patrones histológicos y peculiaridades citológicas que confieren a este grupo una relativa heterogeneidad (3).

La presencia de gran número de células neoplásicas con morfología "en anillo de sello" en un carcinoma urotelial de alto grado no va a conferir un pronóstico distinto aunque el número o proporción de las mismas puede constituir un subgrupo histológico con personalidad propia, infrecuente en esta localización.

\section{CASO CLÍNICO}

Paciente varón de 69 años, fumador de larga evolución, que debuta clínicamente con hematuria intermitente. Se realizaron estudios citológicos seriados de orina observándose células con atipia franca manifestada como hipercromasia, irregularidad nuclear, desproporción nucleocitoplasmática y disposición en grupos bidimensionales con cierta discohesión.

Algunas células mostraban un tamaño de hasta tres veces el de células uroteliales no atípicas adyacentes y en ocasiones se pudo observar la presencia de grandes inclusiones mucinosas citoplasmáticas que desplazaban el núcleo hacia la periferia adoptando tales células un aspecto "en anillo de sello". Tras comunicar tal hallazgo como indicativo de carcinoma se realizó una RTU cuyos 


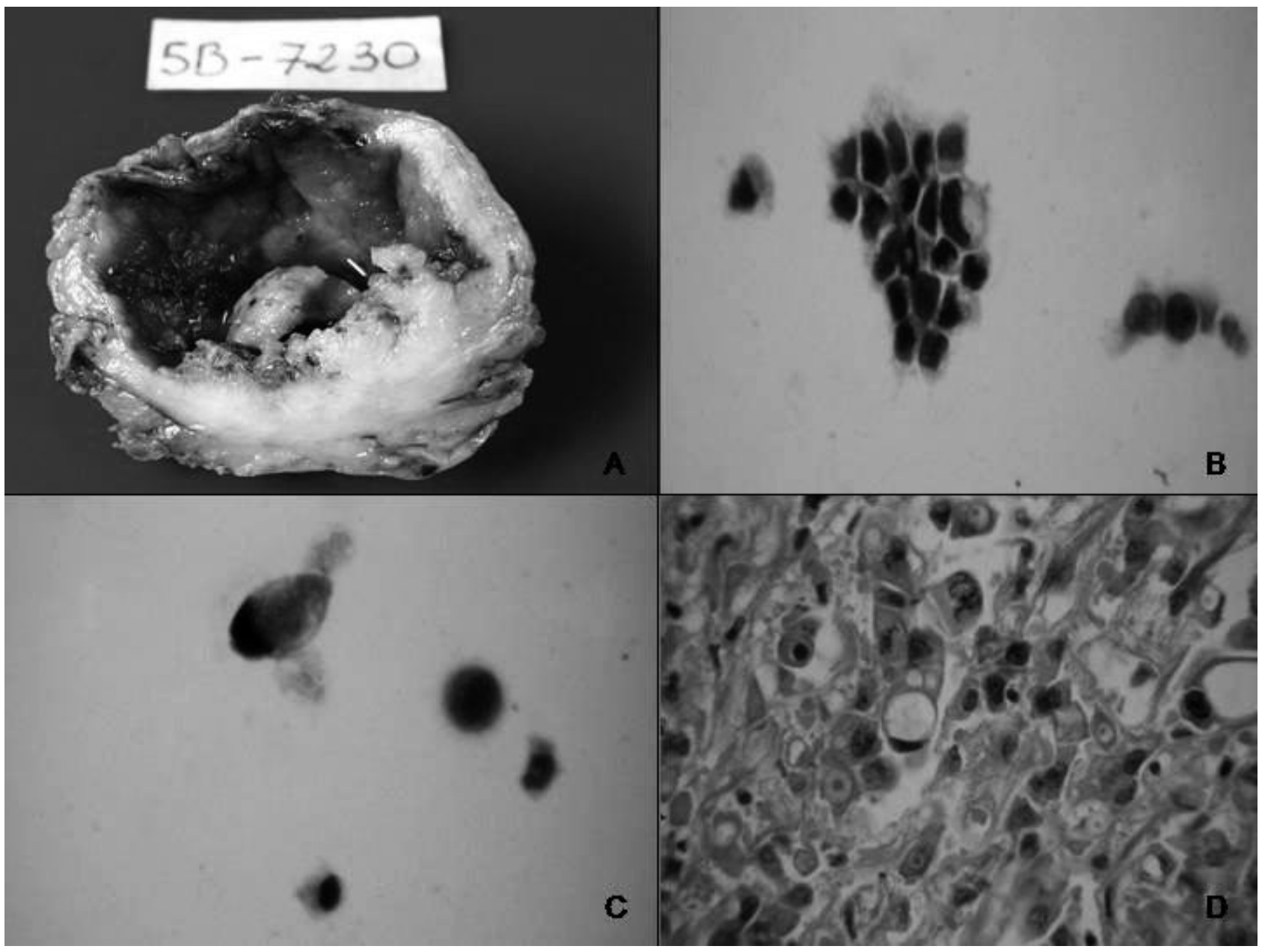

FIGURA 1. Carcinoma urotelial vesical de alto grado con células "en anillo de sello". A) Imagen macroscópica. B) Detalle citológico. C) Células en anillo de sello, detalle citológico. D) Celulas en anillo de sello, RTU.

hallazgos, carcinoma urotelial de alto grado invasivo, conllevaron una cistoprostatectomía radical.

Se recibió una pieza de cistoprostatectomía radical que medía $9 \times 6,5 \times 4 \mathrm{~cm}$. de dimensiones máximas a cuya apertura se podían observar varias formaciones polipoides, la mayor de las cuales medía $1 \mathrm{~cm}$., que se originaban en cara anterior obstruyendo parcialmente la cavidad vesical, que mostraba un mucosa irregular, deslustrada y ulcerada. La pared mostraba un engrosamiento difuso a expensas de un tejido grisáceo y firme que se continuaba con el tejido adiposo perivesical. El resto de la mucosa, de aspecto edematoso, no mostraba lesiones evidentes.

Histológicamente se trataba de una lesión urotelial infiltrante constituida por células con intensa atipia agrupadas en islotes tumorales con variable cohesividad así como un patrón sólido de predominio superficial con amplias áreas de ulceración. En profundidad predominaba un patrón infiltrante con regueros, estructuras pseudoadenoides y células sueltas, algunas de ellas con gran bizarrismo así como gran número de inclusiones mucinosas citoplasmáticas siendo frecuente encontrar figuras de invasión vascular y perineural. A este nivel se apreció un estroma mucinoso positivo a la tinción de PAS, también positiva a nivel de las inclusiones citoplasmáticas anteriormente descritas. Del mismo modo se observaron microabcesos intratumorales aislados.

Con todo ello se realizó el diagnóstico de carcinoma urotelial primario de alto grado (G3) de vejiga urinaria con áreas de adenocarcinoma difuso con células "en anillo de sello", señalando la infiltración del tejido adiposo perivesical (pT3b). No se observó infiltración macro ni microscópica de las vesículas seminales y de la próstata, la cual mostró lesión epitelial de alto grado (PIN de alto grado) tras realizar un estudio microscópico minucioso.

El paciente fue tratado postoperatoriamente con ciclos de radioterapia y controlado por el Servicio de Onco- 
logía detectándose a los seis meses de la intervención múltiples metástasis óseas. Un mes después ingresó en Urgencias por un cuadro de ileo paralíitico falleciendo al día siguiente.

\section{DISCUSIÓN}

El carcinoma urotelial con células "en anillo de sello" es una neoplasia muy poco frecuente a nivel vesical, constituyendo sólo el $0,2-0,6 \%$ de las mismas. No está bien establecido el porcentaje de células "en anillo de sello" necesario para clasificar estas neoplasias como adenocarcinoma puro con patrón de células "en anillo de sello", encontrándose en distintas series cifras tan dispares como el $25 \%$ o el $100 \%$. Hay que señalar que dichas células pueden ser un hallazgo casual o bien un componente minoritario en distintos tipos de carcinomas uroteliales $(1,2)$.
El diagnóstico diferencial hay que establecerlo con adenocarcinomas infiltrantes de órganos adyacentes (colon, próstata....) así como con metástasis de tumores originados en órganos a distancia. Los estudios imunohistoquímicos (PSA, E-caderina, citoqueratina 20, S 100) serán de gran utilidad en estos casos. La presencia de un componente "in situ" y otros patrones de carcinoma urotelial convencional, como en nuestro caso, permiten establecer el origen primario. En las formas "puras", los datos clínicos y radiológicos serán de gran ayuda para establecerlo $(6,8,9,10)$.

Hay que destacar el papel que la citología urinaria puede tener en el diagnóstico de estas neoplasias $(4,5)$; generalmente los hallazgos son los característicos de una neoplasia urotelial de alto grado siendo infrecuente la observación de células en anillo de sello en este tipo de material salvo que dicho componente sea mayoritario o al menos predominante. En cualquier caso los citados

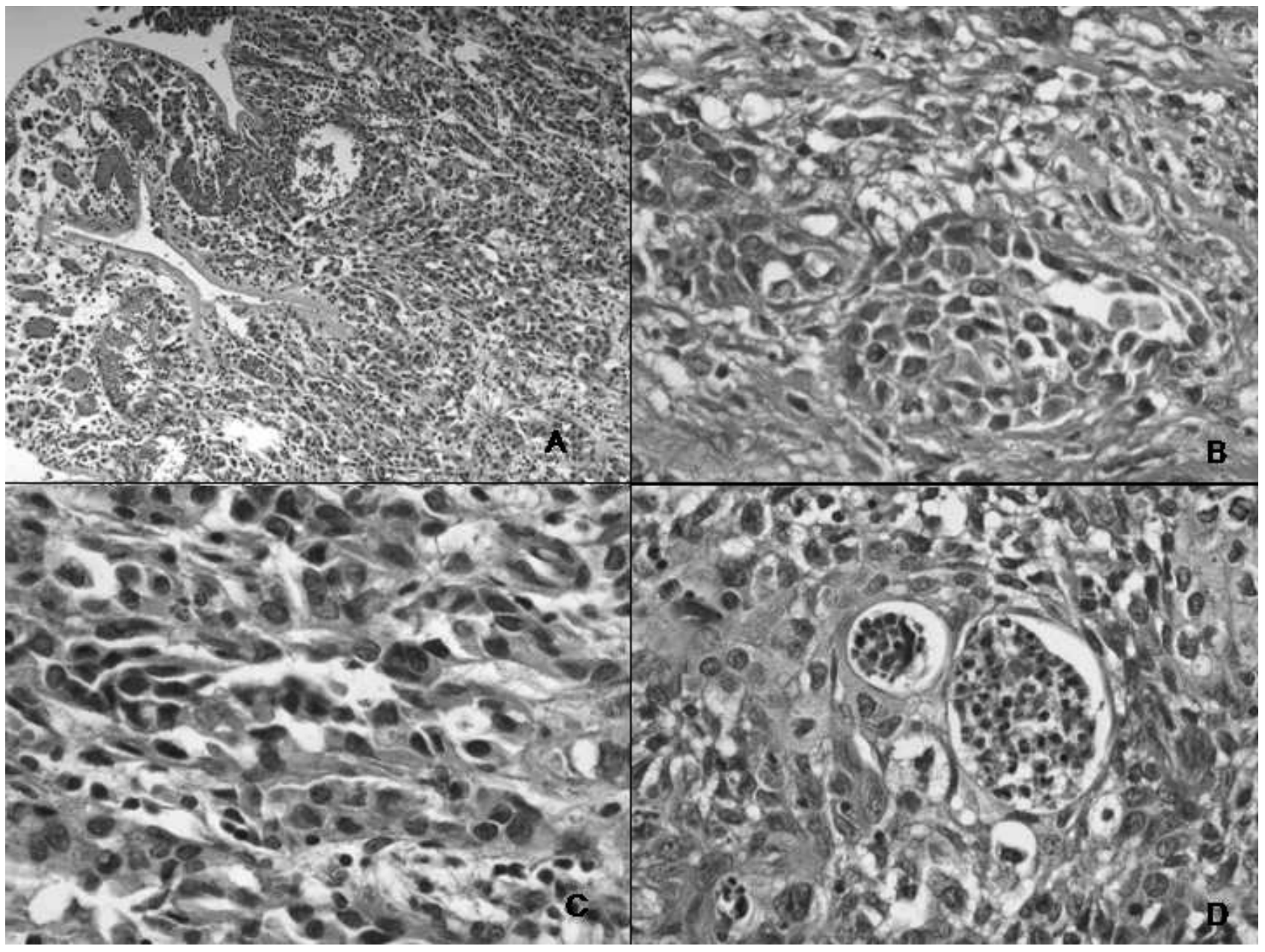

FIGURA 2. Carcinoma urotelial vesical de alto grado con células "en anillo de sello". A) Carcinoma urotelial infiltrante, imagen panorámica 10 x. B) Elementos uroteliales de alto grado y células "en anillo de sello", 40 x. C) Alta atipia nuclear, 40 x. D) Abscesos intratumorales, $40 x$. 


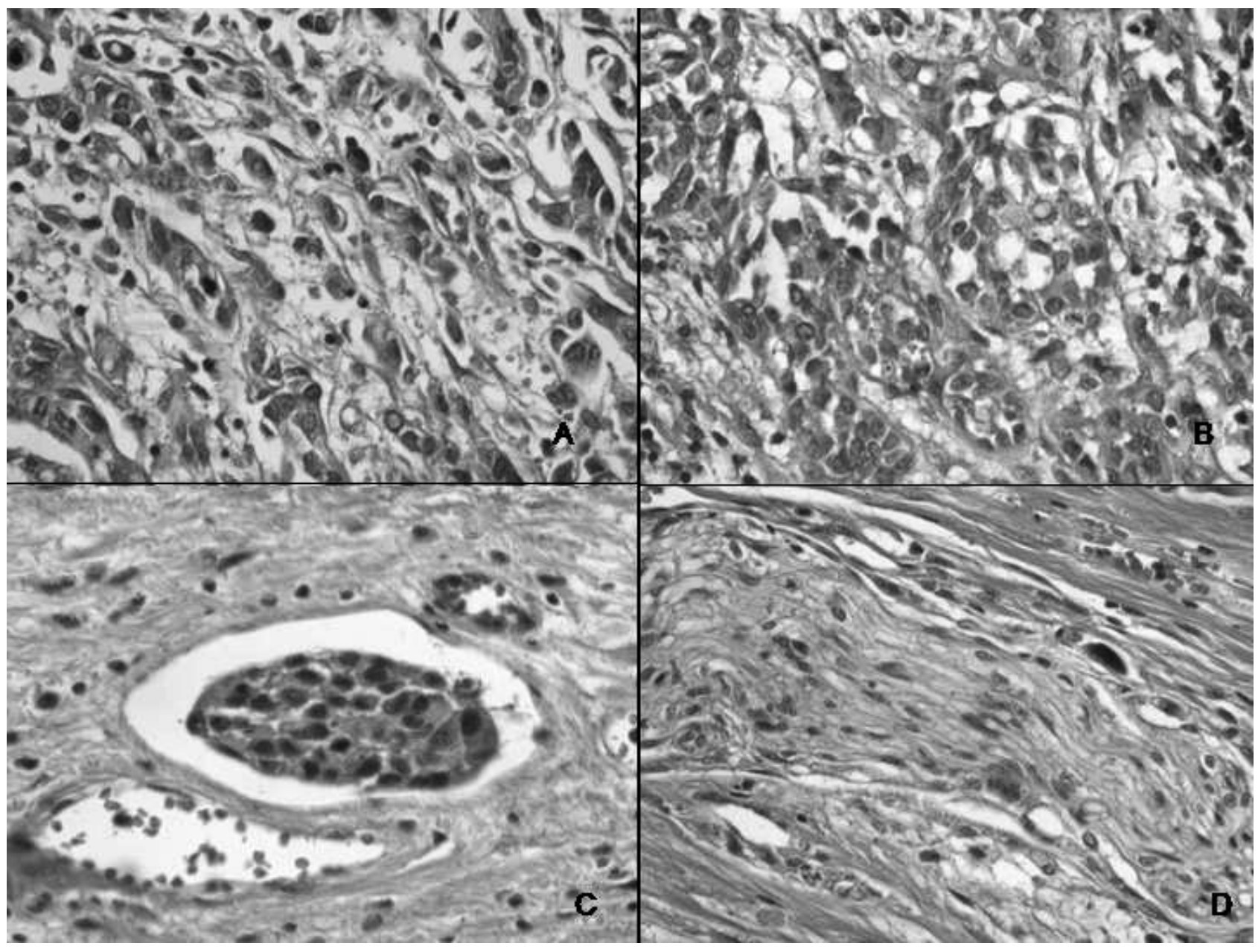

FIGURA 3. Carcinoma urotelial vesical de alto grado con células "en anillo de sello". A) Infiltración tumoral en regueros, 20 x. B) Imágenes peudoadenoides, 40 x. C) Invasión linfática, 40 x. D) Invasión neural, 40 x.

estudios citológicos de orina se realizan tras la aparición de signos o síntomas clínicos/generalmente hematuria aunque se han descrito presentaciones clínicas como oliguria o fallo renal) $(7,8)$, momento en que el proceso neoplásico está lo suficientemente avanzado como para asegurar un mal pronóstico.

En nuestro caso si bien pudo objetivarse una lesión prostática intraepitelial de alto grado, ésta no se relacionaba con un componente invasivo ni existía una relación de continuidad con la neoplasia vesical por lo que fue interpretada como un hallazgo casual independiente.

El contexto clínico y epidemiológico es similar al de otras neoplasias uroteliales aunque se asocian a un peor pronóstico (supervivencia a los dos años del $46 \%$ y $23 \%$ a los cinco, similar a la del carcinoma urotelial grado 3).

La cirugía constituye el tratamiento de elección si bien la quimioterapia juega un importante papel en aquellos casos en que debido a la extensión de la enfermedad o al estado clínico la cirugía no puede ser considerada el tratamiento de primera elección (11).

\section{BIBLIOGRAFÍA Y LECTURAS RECOMENDADAS (*lectura de interés $y^{* *}$ lectura fundamental)}

1. SAPHIR, O.: "Signet Ring cell carcinoma of the urinary bladder". Pathol., 31: 223, 1995.

2. TORENBEEK, R.; KOOT, R.A.C.; BLOMJOUS, C. y cols.: "Primary signet-ring cell carcinoma of the urinary bladder". Histopathology, 28: 33, 1996.

*3. ROBERT, H.; YOUNG, M.D.; JOHN, N. y cols.: "Unusual forms of carcinoma of the urinary Bladder". H. Path., 22: 948, 1998.

4. PINOS PAUL, M.A.; SANZ VELEZ, J.I.; ABAD ROGER, J.: "Primary signet ring cell adenocarcinoma of the bladder". Actas Urol. Esp., 22: 230, 1998. 
*5. SHINAGAWA, T.; TADOKORO, M.; ABE, M. y cols.: "Papillary urothelial carcinoma of the urinary bladder demostrating prominent signet ring cells in a smear. A case report”. Acta Cytol., 42: 407, 1998.

6. CABALLERO GÓMEZ, M.; MARINO DEL REAL, J.; ASUAR AYDILLO, S.S.: "Primary signet ring cell adenocarcinoma of the bladder. Report of a case". Actas Urol. Esp., 24: 749, 2000.

7. WONG, C.; BEGIN, L.R.; REID, M. y cols.: "Oliguria, an unusual presentation of primary signet ring cell adenocarcinoma of the urinary bladder: a case report and review of the literature". J. Surg. Oncol., 70: 64, 1999.

8. YAMAMOTO, S.; ITO, T.; AKIYAMA, A. y cols.: "Primary signet ring cell carcinoma of the urinary bladder inducing renal failure". Int. J. Urol., 8: 190, 2001.

**9. VARO SOLIS, C.; BÁEZ PEREA, J.M.; GARRIDO INSUA, S.: "Signet ring cell neoplasm: unusual histologic variety as primary bladder tumor". Actas Urol. Esp., 26: 297, 2002.

10. MARINO, G.; MOTTA, E.; MOSSO, L.: "Primary signet ring cell carcinoma of the bladder". Minerva Urol. Nefrol., 57: 125, 2005.

11. HIRANO, Y.; SUZUKI, K.; FUJITA, K. y cols.: "Primary signet ring cell carcinoma of the urinary bladder sucessfully treated with intra-arterial chemotherapy alone". Urology, 59: 601, 2002.

\section{Casos Clínicos}

Arch. Esp. Urol., 59, 8 (820-822), 2006

\section{UTILIDAD DEL URO-TAC EN EL DIAGNOSTICO DE PEQUEÑAS LITIASIS: PRESENTACIÓN DE UN CASO.}

Pilar Moreno Granero y José M. Esteban Hernández.

Servicio de Radiodiagnóstico. Unidad de TAC y RM. Consorcio Hospital General Universitario ERESA. Valencia. España.

Resumen.- OBJETIVO:Presentación de un caso de microlitiasis diagnosticada por Uro-TAC Icon TAC multidetector).

METODO: Describimos el caso de un varón de mediana edad con clínica de cólico renal, con dilatación del sistema pielocalicial y de la vía excretora; sin causa objetivada en la urografía intravenosa, al que se le solicita un UroTAC.

RESULTADO: Al realizar el Uro-TAC vemos una microlitiasis de $2 \mathrm{~mm}$ de diámetro, localizada en la porción distal del uréter izquierdo, que junto con la zona edematosa adyacente, produce la obstrucción de la vía excretora.

CONCLUSIONES: El Uro-TAC es una técnica de imagen útil para diagnosticar microlitiasis, que pueden pasar desapercibidas con otras técnicas de imagen. 